\title{
WHATSAPP COMO AMBIENTE DE INTERAÇÕES NA EDUCAÇÃO A DISTÂNCIA: ENSAIOS DE ENCONTROS SÍNCRONOS E ASSÍNCRONOS
}

\author{
I.F.BLAUTH, N.DIAS*, S.SCHERER
Universidade Federal do Mato Grosso do Sul
nelson.dias@ufms.br \\ Artigo submetido em 15/09/2017 e aceito em 09/08/2019 \\ DOI: 10.15628/holos.2019.6298
}

\section{RESUMO}

O artigo aborda discussões sobre o uso de tecnologias móveis em processos de Educação a Distância (EaD). O objetivo foi analisar potencialidades de uso do aplicativo WhatsApp, como ambiente para interações, quando utilizado como espaço de fórum e chat. $O$ estudo foi motivado pela importância de considerar o uso de tecnologias digitais na/para a educação e pensar diferentes possibilidades para a prática pedagógica docente. Nos dois ensaios realizados: chat e fórum, se discutiram artigos sobre a docência na EaD, e tiveram como participantes estudantes de um Programa de Pós- graduação. As análises foram realizadas a partir de estudos teóricos sobre interação com o uso de tecnologias móveis e as possibilidades de comunicação nos espaços de chat e fórum. Pode-se considerar o aplicativo estudado como importante ambiente para comunicação, interação e discussão de ideias, sendo passível de ser explorado na prática docente em processos de EaD, ampliando as possibilidades de uso na Educação.

PALAVRAS-CHAVE: Tecnologia do ensino a distância, Ambiente de aprendizagem, Chat, Educação a Distância.

\section{WHATSAPP AS THE ENVIRONMENT OF INTERACTIONS IN DISTANCE EDUCATION: SYNCHRONOUS AND ASYNCHRONOUS MEETINGS}

\begin{abstract}
This paper discusses the use of mobile technologies in Distance Education (EaD) processes. The goal was to analyze the potentialities of using the WhatsApp application as an environment for interactions when used as forum space and chat. The study was motivated by the importance of considering the use of digital technologies in/for education and thinking different possibilities for teaching pedagogical practice. In the two essays carried out: chat and forum, articles about teaching in EaD were discussed with students of a Post Graduate Degree
\end{abstract}

Program like participants in this essays. The analyzes were carried out from theoretical studies on interaction with the use of mobile technologies and the possibilities of communication in the chat and forum spaces using Whatsapp. It was possible to consider the use of this comunication application as an important environment for communication, interaction and discussion of ideas, it was possible to be explored in teaching practice in $\mathrm{EaD}$ processes, increasing the possibilities of use in Education. 


\section{TECNOLOGIAS MÓVEIS: RECURSOS PARA O ENSINO E APRENDIZAGEM NA EDUCAÇÃO A DISTÂNCIA}

A evolução das tecnologias possibilitou uma mudança de hábito das pessoas e com elas também mudaram as maneiras de comunicação, o espaço físico e o tempo. Nesse percurso, podese dizer que não há uma mudança de hábito apenas, mas sim, uma mudança na produção de sentidos e da formação social do sujeito, o que podemos chamar de cultura digital.

Para Lemos (2004), a cultura digital iniciou quando começou a popularização da microinformática, quando as pessoas passaram a ter acesso ao meio de produção de informação sem depender dos grandes grupos de mídias ou do Estado. Com o fácil acesso do microcomputador e com a transformação e re-contextualização de seu uso, essa ferramenta passa a ser não apenas meio de consumo, mas também com o advento da internet, passa a ser meio de produção individual e/ou coletiva e de rápida disseminação da informação.

$\mathrm{O}$ autor ainda nos mostra fases desse advento. A primeira fase é o uso individual, com software educativo ou programas de entretenimento, ou como ferramenta para o trabalho. É importante notar que nessa fase o computador não era conectado, sendo apenas para uso pessoal. A segunda fase é do computador coletivo, que surge na década de 1990 quando passa a ser conectado à rede mundial. A terceira fase é caracterizada pela mobilidade, ou conhecido como $\mathrm{CCm}$ (computador coletivo móvel). Nessa fase o computador passa a ser móvel como os notebooks, tablets e smartphones, com a característica de sempre estar conectado ao coletivo, com possibilidades de interagir com as redes sociais. Os dispositivos móveis possuem dimensões reduzidas, leves, e o mais importante, são multifuncionais, permitindo ao usuário carregá-los com facilidade em qualquer lugar.

Para Silva (2013), nosso cotidiano reflete nossas práticas com o uso da tecnologia móvel, pois com os smartphones por exemplo, é possível publicar um vídeo, imagem ou áudio com alguns "cliques". Para que isso seja possível é preciso estar conectado à internet e por meio dela compartilhar os momentos que foram registrados, localizar lugares e pessoas, e ainda pode-se compartilhar notícias, abrir o correio eletrônico ou buscar algum documento que esteja nas nuvens, tudo isso feito instantaneamente.

Ainda de acordo com Silva (2013), o usuário móvel pode acessar a web em qualquer lugar que a internet esteja disponível, ônibus, metrô, praça, lojas, escola, na casa de familiares. Isso permite uma redefinição do uso do espaço, criando possíveis "lugares virtuais".

Para essa autora, a internet promove um espaço desconectado do mundo físico, onde os corpos se desprenderiam do físico e desfrutariam de uma liberdade no mundo virtual totalmente fora da condição da realidade. Entretanto, com a mobilidade não é impossível fazer tal afirmação, pois com a popularização dos dispositivos móveis, o espaço físico e o virtual se mesclam e o conceito do desconectado já não cabe mais nessa nova realidade. Emerge agora um novo conceito, denominado "espaço híbrido", e de acordo com Silva (2013), este espaço conecta o físico e o digital, não sendo mais necessário sair do espaço físico para entrar no espaço digital. 
Keegan (2002) afirma que o telefone móvel também pode ser usado nos processos educacionais. Em sua pesquisa, na qual investigou a mobilidade como uma recurso educacional, identificou e analisou 31 exemplos do uso de celulares na educação. $O$ autor chamou esse recurso de $m$-learning (aprendizagem móvel). Para ele, com a internet é possível manter o aluno, mesmo à distância, ligado a instituição, professor e aos colegas da turma bem como os conteúdos a serem lecionados.

Com a convergência de mídias é possível ampliar a aprendizagem por meio do uso de dispositivos móveis. De acordo com Marçal, Andrade e Rios (2005), esses dispositivos permitem fazer anotações, realizar atividades, consultar material na internet, é possível também acessar conteúdos em qualquer lugar e qualquer momento. Ally (2009) complementa essa ideia afirmando que a partir da utilização de tecnologia móvel permite-se que o aluno tenha controle do momento em que ele deseja aprender, bem como do local onde deseja aprender.

Entretanto, Silva (2013) nos lembra que o m-learning não é apenas acessar conteúdo em qualquer lugar, mas sim, propiciar a interação, colaboração, aulas on-line, pesquisa e publicação. Como a tecnologia móvel não é uniforme, a autora chama a atenção de que é preciso diferenciar a metodologia de acordo com os recursos que o dispositivo possui, sendo assim, é necessário conhecer a tecnologia para adequar ela ao contexto educacional. Assim, fica evidente que o foco não é a tecnologia, mas sim mudanças nas práticas pedagógicas decorrentes do objetivo de aprendizagem com a mobilidade.

Complementar à ideia de Silva (2013), as autoras Nichele e Schlemmer (2015) afirmam que os dispositivos móveis emergem de uma geração de tecnologias digitais que tem o potencial de reconfigurar as práticas pedagógicas, e para que esses dispositivos sejam utilizados também para a educação é necessário que algumas demandas sejam atendidas, entre elas: melhor infraestrutura de acesso à internet; mudanças nos processos de formação docente e uma ressignificação do conceito de "sala de aula". Quanto à formação docente, é necessário que os professores tenham oportunidade de conhecer os recursos tecnológicos, mas também que saibam de possibilidades de uso desses recursos, de acordo com seus objetivos e conteúdos que pretendem desenvolver com seus alunos, a fim de promover a construção do conhecimento.

Diante do exposto, neste artigo são apresentadas algumas discussões sobre o uso de recursos móveis em processos de Educação a Distância e tem como objetivo analisar potencialidades de uso do aplicativo WhatsApp, presente na maior parte das tecnologias móveis, como ambiente para interações na EaD, quando utilizado como espaço de fórum e chat.

O WhatsApp foi escolhido por possibilitar um ambiente de comunicação síncrona e também assíncrona, e ainda é um ambiente pouco utilizado como espaço educacional. Por isso pensamos em utilizá-lo como uma experiência, abrindo espaço para a realização de um fórum (espaço de diálogo assíncrono) e um chat (espaço de diálogo síncrono), em ambos discutindo-se textos referentes à docência na Educação a Distância (EaD).

Este estudo foi realizado com estudantes de um Programa de Pós-graduação em Educação, que em uma disciplina optativa ofertada em 2015, estudavam possibilidades e potencialidades das tecnologias móveis para a Educação a Distância. Desta forma, pensando na integração das tecnologias móveis, principalmente o uso do WhatsApp, como recurso para favorecer o ensino e 
aprendizagem, e na reconfiguração da comunicação que é possível quando se faz uso deste, é que foram realizados esses ensaios que aqui analisamos. Para esses ensaios foram convidados e adicionados aos espaços destinados ao chat e ao fórum, os 05 pós-graduandos e a professora desta disciplina. Com os dados obtidos, a partir da interação do grupo durante as discussões no ambiente, iremos analisar e discutir as diferenças que existem na comunicação, quando se utiliza o mesmo recurso, para os dois ambientes de $\operatorname{EaD}$ (chat e fórum).

\title{
2 O WHATSAPP COMO AMBIENTE PARA CHAT E FÓRUM
}

As Tecnologias Digitais de Informação e Comunicação (TDIC) cada vez mais fazem parte de nossas vidas, por meio delas e com o acesso à internet, podemos ter acesso a informações em qualquer hora e local, nos comunicar com pessoas (receber e enviar informações) dos mais diferentes lugares, sem limites de distância, fazer negócios, buscar localização e notícias diversas.

Todos esses usos podem ser realizados com um celular, smartphone, Iphone, tablets, por exemplo. Essas tecnologias são denominadas tecnologias móveis e de acordo com Moran (2013, p. 1), como o próprio nome já diz, essas tecnologias não foram feitas pra serem utilizadas em um "espaço fixo como a sala de aula: elas são feitas para movimentar-se, para levá-las para qualquer lugar, utilizá-las a qualquer hora e de muitas formas."

No campo da Educação, precisamos pensar em usos para os diversos aplicativos que existem nessas tecnologias. Pensar em propostas que possam incorporar esses aplicativos em processos de ensino e de aprendizagem. Pensar em propostas pedagógicas em que se possa fazer uso dessas tecnologias móveis para promover a troca de ideias, o diálogo e também a construção de conhecimentos, a partir de propostas previamente estabelecidas ou então, propostas que sejam de interesse e possam surgir inclusive, dos próprios alunos. Pois de acordo com Cordeiro e Bonilla (2015, p. 272):

\begin{abstract}
As crianças e jovens que vivenciam esses cotidianos têm sinalizado, a partir de suas táticas, do que encontram (laptops, celulares, redes Wi-Fi, planos pré-pagos), que é possível reterritorializar ambientes carentes de fruição e criar dinâmicas mais ricas de trocas, compartilhamento e construção coletiva de saberes, conhecimento e cultura. Estamos passando por transformações profundas cujo foco não está mais na memorização dos conteúdos, pois estes fluem pela rede, mas em como selecioná-los, tratá-los e remixá-los, demandando capacidade de análise, interpretação, síntese, crítica, na busca de uma perspectiva de criação e não de repetição.

Desta forma, pensando em um espaço de Educação a Distância que possa estar integrando as tecnologias móveis, no estudo que realizamos foi proposta a discussão de dois textos, fazendo uso do WhatsApp ${ }^{1}$ que é um aplicativo de mensagens instantâneas, muito utilizado atualmente, que permite que as pessoas interajam umas com as outras por meio do celular. Este aplicativo foi utilizado como ambiente para a realização de discussões sobre os textos em um modelo de chat, diálogo síncrono, e também em um modelo de fórum, diálogo assíncrono.
\end{abstract}

\footnotetext{
1 Dispositivo que permite o envio de mensagens e além disso seus usuários podem criar grupos, enviar mensagens ilimitadas com imagens, vídeos e áudio. Disponível para conhecimento e download em https://www.whatsapp.com/?l=pt_br.
} 
O WhatsApp é um aplicativo de comunicação utilizado por muitas pessoas no dia-a-dia, e que para a EaD aponta como um recurso para realização de encontros síncronos e assíncronos como o chat e o fórum, por exemplo.

Este aplicativo pode ser um ambiente para os processos de ensino e aprendizagem devido a várias potencialidades, sendo que uma delas é a possibilidade de criar grupos de estudantes para determinados assuntos ou temas. Oliveira et al (2014) corroboram com essa ideia, quando afirmam que com o aplicativo é possível criar grupos de até 50 participantes, quantidade essa que atualmente já foi ampliada para que até 256 pessoas possam ser inseridas em um determinado grupo. Outra potencialidade é o envio de mensagens instantâneas e a possibilidade de ver as pessoas online durante o encontro. Desta forma, ao saber quem está online na "sala de batepapo", os questionamentos podem ser direcionados a determinadas pessoas. Além disso, é possível enviar anexos como: arquivos de vídeo, imagens, áudio e outros documentos. É importante lembrar que a interação apenas ocorre de forma síncrona quando o aparelho estiver em conexão com a internet e com uma velocidade estável, para que as mensagens cheguem instantaneamente, e permitam a comunicação imediata, que é uma característica de um encontro no chat.

Para pensar o aplicativo como um ambiente de chat, que propicia interação síncrona entre as pessoas envolvidas é preciso levar em consideração, além de outros fatores, o tempo de digitação do estudante, pois a tela dos smartphones e tablets são de tamanho reduzido, e estes são utilizadas como teclado, podendo demorar mais no feedback da discussão proposta. Nesse sentido, é importante lembrar que o aplicativo já tem uma extensão na página da web, que permite ao estudante transferir a conversa facilmente para a tela do computador e utilizar o teclado convencional para a conversa (para os que ainda preferem digitar nesse tipo de teclado), o nome dessa aplicação é WhatsApp Web, e é encontrada na página do aplicativo (https://web.whatsapp.com/). É importante salientar que o aparelho de celular precisa estar conectado à internet durante todo o processo para que essa extensão funcione no computador.

O potencial desse aplicativo estende-se aos encontros assíncronos também, como um modelo de fórum, por exemplo. Com a tecnologia móvel, o estudante pode participar do fórum em qualquer lugar que esteja, no ônibus, praça, casa, enfim, e o mais interessante no aplicativo, é que o estudante pode postar suas proposições e questões, mesmo não estando conectado à internet, o aplicativo registra a mensagem e assim que encontrar uma conexão com a internet, sua mensagem será enviada ao espaço criado para tal atividade. Nesse sentido, Oliveira et al (2014, p.04), em sua pesquisa sobre mobile learning reforçam a característica de conexão do WhatsApp, quando afirmam que "as mensagens transmitidas quando o dispositivo está fora da área de cobertura ou desligado são automaticamente salvas e recuperadas quando a rede é restaurada ou quando o dispositivo for ligado.".

Os autores ainda relatam sobre a vantagem de não precisar usar nome de usuário e senha para entrar no ambiente do aplicativo, o que minimiza a possibilidade de que os participantes de uma atividade esqueçam o login de acesso.

A partir das potencialidades do "WhatsApp", e de conhecimento de que este está acessível a todos os integrantes do grupo de estudantes analisados neste artigo, foi pensado um ensaio com 
o aplicativo criando um ambiente de chat (síncrono) e um de fórum (assíncrono). Também foi criado um ambiente em que ocorria a organização e planejamento das ações propostas para ocorrer a interação - tanto como chat, ou como fórum - em que um dos integrantes do grupo foi escolhido como tutor para o fórum, pois de acordo com XXXX (XXXX, p. XX), o professor tutor como articulador tem o papel de organizar os espaços e tempos bem como disponibilizar o ambiente virtual para os "encontros e interações com e entre os alunos".

Para o fórum, nas aulas que ocorrem na modalidade de Educação a Distância, geralmente é utilizado um ambiente na plataforma Moodle ${ }^{2}$, mas neste estudo optamos por criar um fórum no WhatsApp, entre os colegas e professora de uma disciplina que faz parte da grade curricular dos cursos de Doutorado e Mestrado em Educação, de uma universidade pública brasileira. Este grupo inicialmente teve acesso ao texto que deveria ser discutido no ambiente. Em seguida foi criado o grupo para discussão no fórum, especificando um período no qual todos deveriam participar do debate, tempo esse que de acordo com Masetto (2010) deve ser o suficiente para que ocorram contribuições de todos os envolvidos e que se avance nas discussões, lembrando que essas discussões devem ser geradoras de conhecimentos mais avançados. Assim o tempo estimado pelo tutor inicialmente foi de dez dias, o qual também lançou no grupo uma pergunta inicial, que deveria ser a geradora da discussão sobre o texto.

Importante citar que a comunicação do início da atividade também foi feita por e-mail, ampliando assim para outras formas de contatos que não ficassem restritas apenas pelo uso de uma opção de tecnologia, - pois o nível de energia da bateria do celular pode acabar, ou o aparelho pode ficar sem sinal - fazendo com que o estudante fique atento e busque em tempo, condições de acesso e participação da atividade proposta.

Para Pereira, Silva e Maciel (2013, p. 101) "fóruns são ferramentas de discussão e troca de ideias, que favorecem a construção coletiva do conhecimento e integração dos alunos entre si, com tutores e professores", mas que diferente do chat, pode ficar disponível por mais tempo, e é um espaço que permite comunicação assíncrona, ou seja, não necessita de respostas imediatas, fato esse que de acordo com os autores "permite que o aluno faça pesquisas e leituras antes de dar sua própria contribuição e/ou responder a de um colega" (Pereira, Silva \& Maciel, 2013, p.107).

Segundo Costa et al. (2006), o fórum é uma atividade de debate e por ser assíncrono permite o tratamento da forma escrita menos coloquial e mais planificada, os autores afirmam que a elaboração pode ser bem estruturada podendo passar por uma revisão antes de ser enviada. E de acordo com Masetto (2010) este espaço de interação permite que cada participante da discussão, entre no espaço sugerido no momento que puder para fazer suas contribuições, e por isso é necessário que seja disponibilizado um tempo maior. Diante disso e da importância do tema a ser discutido, o tempo previsto para as discussões no fórum ficou estipulado conforme já mencionado acima.

Também foi utilizado o WhatsApp como ambiente de chat, por entendermos que este é um ambiente que permite comunicações síncronas, ou seja, é um espaço que permite conversas

\footnotetext{
${ }^{2}$ O Moodle é uma plataforma de código aberto que permite que você construa a solução educacional de acordo com suas necessidades. É baseado em software livre muito utilizado para a Educação a distância. Está disponível em https://moodle.com/.
} 
escritas em tempo real, é uma ferramenta que se assemelha a uma conversa presencial. Os chats permitem "mensagens instantâneas por meio das quais se pode promover interação instantânea entre os membros de uma comunidade virtual ou de um curso de EaD" (Pereira, Silva \& MACIEL, 2013 , p. 106). E de acordo com Masetto (2010), no momento da realização de um chat todos os participantes devem estar conectados, e podem expressar suas opiniões livremente.

Desta forma, o chat em nosso estudo foi sugerido como espaço para discussão de um texto sobre a docência em ambientes virtuais de aprendizagem. O texto foi enviado por e-mail e foi marcada uma data para que todos estivessem disponíveis com horário específico, e com duração de uma hora para a discussão. Além da possibilidade de interações imediatas, o chat tem uma característica interessante que é a maneira como as pessoas se comunicam. No chat: "A escrita é produzida com características da fala por se tratar de uma forma de comunicação que se efetiva de forma rápida e descontraída. Os usuários podem utilizar-se de reduções, abreviações e onomatopeias sem que haja cobranças de correções" (Silva, 2008, p.119).

\section{ANÁLISES E DISCUSSÕES}

Para este estudo, como já foi mencionado, foram realizados dois ensaios no ambiente do WhatsApp: um que permite comunicação síncrona (chat) e outro que permite comunicação assíncrona (fórum). Para os dois ensaios foram propostas leituras de textos sobre a docência na EaD e foram estipulados prazos para as discussões.

Para o chat, foi combinado um tempo para leitura, e foi sugerido uma hora de tempo para as discussões, em um horário que fosse favorável para que todos pudessem interagir com o grupo e expor suas compreensões sobre o texto. Já para o fórum, o tempo sugerido foi de 10 dias, para que todos pudessem ler o texto e expressar suas compreensões, discutir com os colegas suas compreensões do texto, dúvidas ou inquietações que surgiram no decorrer da leitura.

Após a realização das discussões nos dois espaços (chat e fórum), no ambiente do WhatsApp, foi analisada a interação e a comunicação ocorrida nesses dois ambientes. Cada ambiente foi analisado em separado, com a intenção de identificar algumas características de comunicação no chat e no fórum.

\subsection{O chat no Whatsapp: ensaios de um ambiente de interação}

O chat foi um espaço criado no ambiente do WhatsApp, com a finalidade de discutir alguns aspectos importantes de um texto ${ }^{3}$ em que se discute a formação de professores para a EaD. Este chat teve a duração de uma hora, e contou com quatro participantes, sendo que três deles participaram efetivamente das discussões, ou seja, ficaram conectados durante todo o tempo, participaram das discussões sobre o texto estudado, puderam expressar suas ideias e compreensões, ou então tirar dúvidas, e dessa forma, tiveram a oportunidade de construir juntos, compreensões sobre a ideia central do texto discutido. Além disso, podiam interagir com outras

\footnotetext{
${ }^{3}$ Aretio, L. G. (2009). Docentes en Ambientes Virtuales. In: Aretio, L. G. Estudios de Educación a distancia ¿ Por qué va ganando la Educación a distancia? Universidad Nacional de Educacion a distancia. Librería UNED: Madrid. p.269313.
} 
situações que aconteciam durante as discussões naquele espaço. É interessante constar que durante a realização deste chat, cada participante estava em um espaço físico diferente, dois em cidades distintas e dois na mesma cidade, mas em locais diferentes, inclusive um deles estava parado em uma rodovia, em função de problemas com o carro, e utilizou-se da internet móvel para participar no chat, e que estes serão identificados na análise como P1, P2, P3 e P4.

No chat, a discussão foi mais dinâmica, a interação entre os participantes foi direta, pôdese observar uma conversa entre pessoas que se conheciam, no caso colegas, e que se sentiam à vontade conversando. Em alguns momentos houve ironia nas falas, outras vezes preocupação com o colega, como veremos a seguir, mas acima de tudo, houve debate sobre o conteúdo do texto, que era o objetivo inicial do momento virtual possibilitado pelo chat. Os participantes puderam expressar o que pensavam a cada momento, sem ter que pedir a vez para falar. O que pode ser considerado como uma vantagem do uso desse recurso para potencializar discussões, uma vez que ao mesmo tempo, todos os integrantes do grupo podem expor suas ideias. Isso corrobora com as ideias de que, em um chat "a turma não precisa estar em silêncio para receber sua contribuição" (PEREIRA; SILVA; MACIEL, 2013, p. 107).

No vocabulário utilizado notou-se que em vários momentos ocorreu o que Silva (2008) já havia observado, que "enquanto a conversa se efetiva, risadas e expressões faciais da forma convencional, são reproduzidas com símbolos e grafias que tentam aproximar-se do som na linguagem falada".

Para iniciar a conversa no chat, um dos participantes lançou mão da expressão "Buenas Noches!" (Justificada pelo fato do texto a ser debatido estar escrito originalmente no idioma espanhol). Outra participante, inicia questionando: "E aí galera o que acharam do texto" (o que denota certa familiaridade com os colegas). A discussão no chat se inicia desse jeito:

P1: E aí galera o que acharam do texto?

P1: em espanhol ainda kkkk.

P2: nossa... o texto é relativamente denso, mas muito esclarecedor

P1: eu senti que no início ele fala do compromisso que um professor que trabalha a distância deve ter, mas eu acho que esse compromisso todo professor deveria ter, independente do ambiente em que está trabalhando.

Até que entra na conversa, o P4 e se expressa com a seguinte figura " ᄀ₹", o que imediatamente causa espanto no P2, que pergunta "ué, vc não gostou do texto, P4?", e P3, que já estava digitando seu texto enquanto esta conversa ocorria, diz o seguinte: "sim... essa característica ele ressalta como sendo algo essencial para a educação como um todo, independente da modalidade...". Esse movimento denota que no chat as discussões podem mudar rapidamente de foco, e que enquanto P3 estava prosseguindo a discussão, preocupado em digitar sua opinião sobre o texto, outras conversas estavam ocorrendo no grupo.

E dando sequência ao diálogo, P4 envia a foto do seu carro e diz "Tô com o carro quebrado!", "Mas prossigam q to acompanhando!". De imediato P2, observando a foto enviada diz: “- nossa... pelo menos o farol tá funcionando!". Demonstrando espanto e preocupação com o colega, ao mesmo tempo com certo tom de ironia. Para dar sequência ao diálogo, referindo-se 
ao texto, P2 diz: "continuando... gostei bastante do texto pq o autor traz as diversas características que o professor da EaD 'pode' ter... não apenas o professor, mas toda a equipe pedagógica... uma vez que o autor ressalta que existem diversas funções!". O que representa que o foco da discussão permanecia no texto.

E assim a discussão no chat prosseguiu, P4 apenas acompanhou, não participando com postagens da discussão. E os outros três participantes discutiram pontos que consideram fundamentais do texto:

P3: Em relação a essa característica e habilidades de professor "camaleão" o autor chama a atenção sobre os diferentes tipos de perfis dos "maestros" tem aqueles que acham que a tecnologia dará conta de tudo e aqueles que se opõe radicalmente [..]

P2: siiiiiim, P3!!! os tecnófilos e os tecnófobos... eu gostei dessa parte tb $[\ldots]$

P3: $O$ que vcs acharam do modelo de EaD da UNED? P2: no ítem 5 o autor inicia com uma citação muito bacana, vcs viram? P2: a UNED tem sido referência no quesito de EaD, neh?"

Nesse trecho da conversa observa-se a interação dos participantes discutindo o texto proposto: P3 comenta sobre os tipos de perfis que os professores tem com relação ao uso da tecnologia fazendo referência ao texto estudado, e P2 complementa citando as definições propostas pelo autor sobre esse assunto. Em seguida, P3 faz um questionamento sobre o modelo de EaD colocado no texto, e logo P2 lembra uma citação do texto que achou interessante e traz um outro questionamento sobre o modelo de EaD citado no texto.

Observa-se que o conteúdo do texto sempre é discutido, questionado, comentado. Durante a conversa surgiram representações escritas que podem ser entendidas como risos (kkkkkk, rsrsrsrsr), exclamações (nossa, siiiiimm), abreviaturas, que são comuns entre as pessoas que se comunicam pelo WhatsApp (vc, tb, pq, neh, eh), figuras (foto do carro estragado, figura de uma professora que está inserida em um ambiente com tecnologias, não sabendo o que fazer com elas e acaba utilizando-as de forma tradicional), emoticons ( $\mathcal{F} \odot$ ) e outras representações que são possíveis devido a interação rápida disponível nesse ambiente.

Outra observação interessante que se pôde fazer, é a de que durante a realização do chat, P4 pôde participar (dando seu recado), e acompanhando as discussões (pois estava inserido no grupo), mesmo em uma rodovia, com o carro estragado, o que denota, que essa "era da mobilidade" proporciona essa "mudança de tempo e espaço" para a aprendizagem, pois de acordo com Silva (2013, p. 130), com o uso dos dispositivos móveis, "além do tempo e do espaço, o conteúdo da comunicação é ressignificado: a escola entra em casa, e a casa entra na escola, os amigos, a família, a comunidade..., os espaços e os tempos informacionais são ampliados".

No caso do chat realizado nesse ambiente, pôde-se notar que mesmo sendo realizado no período noturno, e fora da sala de aula, por meio do WhatsApp foi possível propor um espaço de diálogo sobre um texto, que era o objetivo inicial. E também que uma hora é um tempo razoável, mas que em função da complexidade do texto, muitos pontos não foram discutidos. O que nos leva a refletir sobre a possibilidade de um tempo maior, ou discussões mais pontuais em espaços 
de chat. Ou até mesmo estender a atividade para outro tipo de espaço na EaD, como a wiki ou fórum, como é colocado pelo $\mathrm{P} 3$, quando este abre espaço para possíveis questionamentos, que por algum motivo poderiam ter ficado fora da discussão, e sugere um outro ambiente de encontro:

P3: bom pessoal, não vamos conseguir esgotar todos os pontos do texto, uma hora passa muito rápido kkk [...]

P3: podemos continuar o debate no fórum.

\subsection{O Fórum no Whatsapp: espaço de interações assíncronas}

O fórum, foi um ambiente criado no WhatsApp, no qual um grupo foi criado com o objetivo de discutir um texto ${ }^{4}$ sobre a poli docência em ambientes virtuais de aprendizagem. A este grupo tiveram acesso a professora da disciplina, o tutor e quatro participantes, sendo que estes serão considerados como tutor, professora, P1, P2, P3 e P4 na análise. Foi informado inicialmente um período (10 dias) em que este ambiente ficaria disponível e foi lançada uma pergunta inicial que deveria iniciar a discussão sobre o tema proposto no texto. Assim, a proposta do fórum foi a seguinte:

Boa tarde Pessoal! Vamos iniciar a discussão do nosso texto? O texto que iremos debater é: "Prática polidocente em ambientes virtuais de aprendizagem: reflexões sobre questões pedagógicas, didáticas e de organização sociotécnica" Para iniciarmos, proponho o seguinte questionamento: Segundo os autores, o que é a prática polidocente em ambientes virtuais de aprendizagem? Esse texto já foi enviado para o e-mail de vocês. O Fórum foi criado em um grupo de WhatsApp, caso alguém não tenha sido adicionado, favor comunicar por e-mail. O período de discussão iniciará às 17:00 de hoje (17/02/2016) e encerrará às 17:00 do dia 27/02/2016. Grande Abraço! (fala do tutor fazendo a orientação para o fórum)

Neste enunciado fica bem claro o foco da discussão e o tempo previsto. Porém inicialmente, observou-se pouca interação no espaço, ninguém compartilhava suas ideias, até que P1 expôs sua compreensão do texto lido (em forma de um texto resumindo o que compreendeu), e P2 também o fez da mesma forma. Ao ler os textos no grupo, a professora da disciplina, que também tinha acesso ao fórum afirmou: "Pessoal... Uma dica para os trabalhos aqui fluírem. Escrevam mensagens menores...sínteses, questões centrais e tal... Vamos lá? Tenho sentido a falta de alguns... (⿻)", chamando os outros participantes a darem suas opiniões e discutirem o texto.

Após ler também os textos de P1 e P2, que expressaram no fórum sua compreensão do texto lido, e por perceber que alguns colegas ainda não tinham participado, o tutor novamente entra em ação, agora chamando a atenção para que todos participem, ele diz: "Olá Pessoal! O prazo está acabando e precisamos de mais alguns pontos para discussão. Acredito que pelo menos três postagens de cada, em momentos diferentes já dá pra termos uma boa discussão sobre o tema. E aí vamos debater???" O que denota que o tutor estava atento ao que estava acontecendo, e devido a não participação do grupo, percebe que inicialmente não exigiu quantidade mínima de

\footnotetext{
${ }^{4}$ Mill, D. (et. al.). (2013) Prática Polidocente em ambientes virtuais de aprendizagem: reflexões sobre questões pedagógicas didáticas e de organização sociotécnica. In: Maciel, C. Educação a distância: Ambientes virtuais de aprendizagem. Cuiabá: EdUFMT. p. 219-259.
} 
postagens, e por isso o faz naquele momento, fazendo novos questionamentos direcionados à P1 e P2 que já haviam dado sua contribuição inicial. Apenas no dia anterior ao encerramento do prazo é que a discussão começou a fluir com mais intensidade.

Nesse fórum observou-se que a discussão ficou mais pautada no texto, com discussões e afirmações melhor fundamentadas, pois de acordo com Pereira, Silva e Maciel (2013, p. 101), "este ambiente permite a proposição de discussões que demandam contribuições mais planejadas e reflexivas". E neste fórum, mesmo sendo realizado também via WhatsApp, a comunicação foi mais formal, diferente da ocorrida no chat, houve preocupação em expor ideias que condiziam com o texto e também com a escrita do mesmo. As perguntas e discussões foram direcionadas de acordo com as afirmações que se queria atingir, como por exemplo:

P3: P2, quando você diz que na EaD devemos pensar em formas de que "a aprendizagem pode ser otimizada nos espaços virtuais", você está se referindo a ferramentas de IA que possam "automatizar" alguns processos e agilizar a colaboração/interação entre professores e alunos?

P2: Olá pessoal, boa tarde! P3, pensei no "otimizar o processo de aprendizagem" no sentido de o professor tutor ter ao seu dispor condições para promover a interação entre os sujeitos sob as diversas formas de comunicação, uma das principais características que devem estar presentes nos ambientes virtuais, com o foco na aprendizagem. E eu acredito que para que o professor tenha esse suporte, e como o próprio texto diz, se faz necessário o apoio técnico, pedagógico de outros profissionais que são direta ou indiretamente responsáveis pelo "fazer acontecer" desses ambientes. Quanto a ferramentas de IA que possam "automatizar" alguns processos, confesso que não consigo enxergar essa possibilidade no sentido da colaboração/interação, o que você acha?

P3: acho que podem ser usadas como início, provocação, mas jamais isoladas... (trecho de um diálogo entre dois participantes).

No trecho exposto anteriormente se pode observar que durante o diálogo, P3 tem uma dúvida em relação ao que P2 pensa em relação à "aprendizagem ser otimizada nos espaços virtuais", ao que P2 já responde que pensou ao utilizar as tecnologias digitais em ambientes virtuais, em que "o professor tutor tenha ao seu dispor condições para promover a interação entre os sujeitos". E ainda expõe sua ideia a respeito desse assunto, finalizando com mais um questionamento a P3. O que nos faz refletir que ao mesmo tempo que os participantes discutiam suas ideias, também estavam fazendo questionamentos, ou seja, buscavam no colega uma resposta para seus questionamentos ou compreensão de suas ideias sobre o que estava exposto no texto estudado.

No fórum realizado neste ambiente, houve interação maior apenas no último dia, e após o tutor fazer uma observação de que todos deveriam ter um número mínimo de postagens, o que nos faz refletir que talvez esse possa ter sido um fator para que as discussões não tenham ocorrido antes, ou então, podemos considerar aquele ditado brasileiro que diz que "deixamos tudo para a última hora", sendo como um fator que impediu que discussões mais aprofundadas, e entre todos os participantes, pudessem ocorrer nesse espaço.

Enfim, nos encontros realizados nos dois "espaços virtuais" aqui analisados, houve interação e envolvimento dos participantes, e de forma diferenciada, foram representadas suas 
discussões. No espaço chat, a discussão ocorreu de forma mais dinâmica, com interação direta, fato esse que se justifica por esse espaço ser caracterizado como síncrono, com todos os participantes presentes ao mesmo tempo. Porém, no espaço fórum, um espaço assíncrono, as ideias também foram expostas de forma articulada e interativa, mas em tempos diferentes, possibilitando igualmente discussão do texto.

\section{CONSIDERAÇÕES FINAIS}

Atualmente, a cultura digital, na qual está inserida a sociedade mundial, possibilita que diversos meios de interação e comunicação sejam explorados, de forma que a maioria das pessoas tenha acesso à informação rápida e de maneira independente. Essas várias possibilidades podem também ser utilizadas na área de educação, com a integração das novas tecnologias às práticas docentes.

Com o advento do m-learning, os dispositivos móveis passaram a ser considerados como recursos possíveis de ensino e de aprendizagem, considerando que eles promovem a interação entre as pessoas de uma comunidade, permitindo a rápida troca de informações. Diversos aplicativos constantemente desenvolvidos para uso nos dispositivos móveis possibilitam que atividades pedagógicas sejam realizadas a partir dos mesmos, seja de forma síncrona ou assíncrona.

Esse artigo objetivou analisar o aplicativo "WhatsApp" como um potencial ambiente de interações na EaD, sendo que neste foram desenvolvidas duas atividades distintas - chat e fórum - para discussão de textos anteriormente estudados. A partir da análise dos dados obtidos com a realização dos ensaios, pôde-se considerar o aplicativo estudado como importante ambiente para comunicação, interação e discussão de ideias, sendo portanto, passível de ser explorado na prática docente em processos de Educação a Distância.

Assim, diante das observações, surgem vários questionamentos e inquietações que podem ser tema para novas pesquisas e análises. Será que o WhatsApp, com outros grupos e momentos, também pode ser utilizado como ambiente de chat para propiciar interações e aprendizagem? $\mathrm{E}$ quando nos referimos ao fórum, será que as participações não foram tão efetivas, devido a falhas gerenciais? Como professores ou tutores podem potencializar o uso deste dispositivo na Educação a Distância? E qual deveria ser a formação dos professores que atuam na EaD para usar efetivamente este dispositivo? O WhatsApp pode ser utilizado durante as aulas como um potencializador de discussões, para que todos os alunos possam expressar suas ideias? Como esse aplicativo pode interferir ou então favorecer a aprendizagem dos alunos?

Enfim, esse é apenas um passo que pode ser o gerador de muitas pesquisas e discussões ainda, pois representa mais um desafio para a Educação, ensinar e aprender a partir das interações vivenciadas com as tecnologias móveis.

\section{REFERÊNCIAS}

Ally, M. (Ed.). (2009). Mobile learning: Transforming the delivery of education and training. Edmonton: Athabasca University Press. 320 p. 
Costa, C. J. de S. A., Paraguaçu, F., \& Mercado, L. P. L. (2006). Parâmetros para análise das ferramentas de aprendizagem colaborativa na internet. In: Anais do virtual educa 2006, Bilbao, Espanha, pp. 1-19.

Cordeiro, S. F. N., \& Bonilla, M. H. S. (2015). Tecnologias digitais móveis: reterritorialização dos cotidianos escolares. Educar em revista, Curitiba, Brasil, n. 56, p. 259-275, abr./jun. Editora UFPR. Recuperado em Agosto, 2017, de http://www.scielo.br/pdf/er/n56/0101-4358-er-5600259.pdf.

Keegan, D. (2002). The future of learning: from elearning to mLearning. Recuperado em agosto, 2017, de http://learning.ericsson.net/mlearning2/project_one/book.html.

Lemos, A. (2004). Cibercultura e mobilidade: a era da conexão. In: Leão, L. (org.). Derivas: cartografias do ciberespaço. São Paulo. Annablume.

Marçal, E., Andrade, R., Rios, R. (2005). Aprendizagem utilizando dispositivos móveis com sistema de realidade virtual. RENOTE: Revista novas tecnologias na educação, 3. Maio.

Masetto, M.T. (2010). Mediação pedagógica e o uso da tecnologia. In: Moran, J.M., Masetto, M. T., \& Behrens, M.A. (2010). Novas tecnologias e mediação pedagógica. Campinas, SP: Papirus, 17ạ edição.

Moran, J. M. (2013). Desafios que as tecnologias digitais nos trazem. Recuperado em 20 de agosto, 2017

de http://www.eca.usp.br/prof/moran/site/textos/tecnologias_eduacacao/desaf_int.pdf.

Nichele, A. G., \& Schlemmer, E. (2015). Percursos de uma prática pedagógica com o uso de tecnologias móveis e sem fio na licenciatura em química. In: 37ạ Reunião Nacional da ANPED, 37, 2015, Florianópolis: UFSC. p. 1 - 18.

Oliveira, E.D.S., Anjos, E.G., Oliveira, F.S., Sousa, H.M., \& Leite, J.E.R. (2014). Estratégias de uso do whatsapp como um ambiente virtual de aprendizagem em um curso de formação de professores e tutores. Recuperado em agosto, 2017, de http://webcache.googleusercontent.com/search?q=cache:http://sistemas3.sead.ufscar.br/oj s/index.php/2014/article/view/835/425\&gws_rd=cr\&dcr=0\&ei=m8CoWaWQFoapmwGZqbu gDQ.

Pereira, V. C., Silva, C.B.M., \& Maciel, C. (2013). Recursos e atividades para materiais autoinstrucionais em AVA. In: Maciel, C. (org.). Educação a distância: Ambientes virtuais de aprendizagem. Cuiabá: EduFMT.

Silva, E. D. (2008). Gêneros digitais como material didático nas aulas de língua portuguesa. In: Mercado, L. P. L. (org.). Práticas de formação de professores na educação a distância. Maceió: EDUFAL.

Silva, M. G. M. (2013). Mobilidade e construção do currículo na cultura digital. In: Almeida, M.E.B., SILVA, B.D., Dias, P. (org.). Cenários de inovação para a educação na sociedade digital. São Paulo: Edições Loyola. 